BHUMI: Jurnal Agraria dan Pertanahan

Received: March 20, 2021; Reviewed: May 17, 2021; Accepted: August 26, 2021.

To cite this article: Salim, M.N., Utami, W., Wulan, D.R., Pinuji, S., Mujiati, Wulansari, H., Dwijananti, B.M. (2021). Menyoal Praktik Kebijakan Reforma Agraria di Kawasan Hutan, Bhumi, Jurnal Agraria dan Pertanahan, 7 (2), 149-162.

DOI: 10.31292/bhumi.v7i2.476

Copyright: @2021 M Nazir Salim, Westi Utami, Diah Retno Wulan, Sukmo Pinuji, Mujiati, Harvini Wulansari, Bunga Mareta Dwijananti. All articles published in Jurnal Bhumi are licensed under a Creative Commons Attribution-ShareAlike 4.o International license.

Policy Forum

\title{
MENYOAL PRAKTIK KEBIJAKAN REFORMA AGRARIA DI KAWASAN HUTAN
}

\author{
M. Nazir Salim, ${ }^{{ }^{*}}$ Westi Utami ${ }^{2}$, Diah Retno Wulan ${ }^{3}$, Sukmo Pinuji ${ }^{4}$, Mujiati5, \\ Harvini Wulansari ${ }^{6}$, Bunga Mareta Dwijananti ${ }^{7}$ \\ ${ }^{12456}$ Sekolah Tinggi Pertanahan Nasional \\ 3Kementerian Agraria dan Tata Ruang/Badan Pertanahan Nasional \\ ${ }^{7}$ Kantor Wilayah Badan Pertanahan Nasional Provinsi Riau \\ *Koresponden E-Mail: nazirsalim@stpn.ac.id
}

\begin{abstract}
The Agrarian Reform (RA) policy, especially land redistribution from the release forest areas, is considered slow. This was caused by several problems in the field, namely: leadership, institutions, regulations, and RA subjectsobjects. Effective strategies to implement $R A$ at central and regional levels has not been found, particularly on leadership and coordination between sectors at site level. This study is presented in the form of a policy forum by closely reviewing findings and solutions to RA practices in forest areas. Analysis, reduction, and interpretation of qualitative data were carried out to draw conclusions on real practices of $R A$ at site level in the last three years. At macro level, the authors' findings confirm that the practice of RA experiences a fairly systematic problem due to the weakness of key actors controlling the implementation of RA, the ineffectiveness of the established institutions, and different interpretations of regulations impacted on the differences in understanding RA objects in the field. These findings emphasized that, resoundingly, strategic program of $R A$ has not yet become a common agenda to be implemented in the framework of creating justice and welfare for the entitled people.
\end{abstract}

Keyword: Agrarian reform policy, PPTKH, GTRA, TORA, release of forest area

Abstrak: Kebijakan Reforma Agraria (RA) khususnya redistribusi tanah dari objek pelepasan kawasan hutan dianggap lambat. Pelambatan tersebut disebabkan karena beberapa problem di lapangan, yakni: kepemimpinan, kelembagaan, regulasi, dan objek-subjek RA. Sampai saat ini, belum ditemukan cara yang efektif untuk menjalankan tata kelola RA di level pusat dan daerah, khususnya kepemimpinan dan koordinasi antarsektor di level tapak. Kajian ini dimaksudkan untuk memetakan problem dan menawarkan solusi dengan basis observasi dan studi di lapangan selama tiga tahun terakhir (2018-2020). Studi ini disajikan dalam bentuk policy forum dengan me-review secara padat temuan-temuan dan solusi atas praktik RA di kawasan hutan. Analisis, reduksi, dan tafsir atas data-data kualitatif dilakukan untuk menarik kesimpulan, bagaimana sesungguhnya praktik RA di level tapak dalam tiga tahun terakhir. Secara makro, temuan penulis mengkonfirmasi bahwa praktik RA mengalami problem yang cukup sistematis akibat lemahnya aktor-aktor kunci pemegang kendali RA, tidak efektifnya kelembagaan yang dibentuk, dan perbedaan tafsir atas regulasi yang berdampak pada perbedaan pemahaman atas objek RA di lapangan. Berbekal temuan tersebut, secara meyakinkan program strategis RA belum menjadi agenda bersama untuk dijalankan dalam kerangka menciptakan keadilan dan kesejahteraan untuk masyarakat yang berhak.

Keyword: Kebijakan RA, PPTKH, GTRA, TORA, Pelepasan Kawasan Hutan 


\section{A. Pendahuluan}

Reforma Agraria (RA) di berbagai wilayah masih menjadi isu agresif yang didahului dengan ketidakstabilan dan kekerasan baik di kawasan hutan maupun non hutan (Lanzona, 2019, Steinebach, 2017, Dhiaulhaq \& McCarthy, 2020). Isu RA terus disuarakan terutama di negara-negara dengan problem dan ketimpangan penguasaan lahan yang cukup tinggi, khususnya di Asia, Amerika Latin, dan Afrika (Fraser, 2008, Ramutsindela \& Hartnack, 2019, Jakaza, 2019, Akinola, 2018). Sekalipun terdapat studi yang justru menunjukkan bahwa program RA ikut menyumbang berkurangnya lahan pertanian dan produktivitasnya (Adamopolous \& Restuccia, 2019), yang diduga sebagai konsekuensi dari individualisasi tanah sebagaimana dikritik oleh Platteau (1996), kemudian lokasi redistribusi yang tidak tepat dan luasan lahan redistribusi yang kecil (Sirait, 2017). Kesemua itu ikut menyumbang dan memudahkan pasar bekerja dalam hal peralihan tanah.

Di Indonesia RA juga menjadi isu penting sejak Reformasi 1998, kemudian meningkat pada periode Presiden Joko Widodo. Di banyak wilayah Indonesia (Lucas \& Warren, 2007, Salim, 2017, Gilbert \& Afrizal, 2019) agresivitas isu RA didahului dengan ketidakstabilan (berupa berbagai varian gerakan protes penguasaan lahan). Kelanjutannya ditandai dengan isu RA sebagai alat untuk mengumpulkan dukungan dari akar rumput. Politisasi RA menjadi bagian rutin dalam kampanye-kampanye untuk meraih dukungan suara sekalipun ditengarai platform masing-masing partai berbeda. Dalam bahasa Tania Li, land reform abad kedua puluh satu melibatkan lebih banyak pelaku dengan beragam agenda (Li, 2021).

Walaupun demikian, secara formal, RA telah dilembagakan dan dibangun infrastruktur hukum dalam rangka penyelesaian konflik lahan, redistribusi tanah kepada masyarakat, serta identifikasi objek-objek RA. Terbitnya Perpres No. 88 Tahun 2017 (dan Perpres No. 86 Tahun 2018) bertujuan untuk menyelesaikan status tanah dalam kawasan hutan yang dikuasai masyarakat. Dengan kehadiran perpres tersebut kemudian dibentuk struktur organisasi Tim Inventarisasi dan Verifikasi Penguasaan Tanah dalam Kawasan Hutan (Tim Inver [PTKH])르 dan Gugus Tugas Reforma Agraria (GTRA) untuk menjalankan program yang kemudian dikampanyekan sebagai program strategis nasional (Tjandra, 2020, Salim, dkk., 2021). Agenda ini pertama kalinya dalam dua puluh tahun terakhir, RA masuk dalam program prioritas.

Dua agenda besar redistribusi tanah dengan objek pelepasan kawasan hutan dan non kawasan hutan masih menemukan banyak persoalan, khususnya redistribusi dengan objek kawasan hutan. Target redistribusi tanah dengan objek dari kawasan hutan (pencadangan dan pelepasan kawasan hutan) lebih besar jumlahnya dibanding dengan objek non kawasan hutan. Berdasarkan sumber resmi Kementerian Lingkungan Hidup dan Kehutanan (KLHK) dalam Peta Indikatif yang sudah dilakukan revisi ke-5 pada September 2020, terdapat sekitar 4,8 juta hektar lahan yang ditargetkan oleh pemerintah (WebGis KLHK, 2021, Salim \& Utami, 2019), sementara angka resmi dalam RPJMN adalah 4,1 juta hektar. Faktanya, setelah lima tahun berjalan, capaiannya masih dianggap rendah. Klaim Kementerian Agraria dan Tata Ruang/Badan Pertanahan Nasional (Kementerian ATR/BPN) sampai awal 2021 baru terdistribusi sekitar 384.058 bidang (seluas 211.035 Ha) atau sekitar 5,15\% (Dirjen Penataan Agraria, 2021).

Laporan Dirjen Penataan Agraria menyebutkan, baru pada tahun 2019-2020 bisa dilakukan redistribusi tanah dari Tanah Objek Reforma Agraria (TORA) pelepasan kawasan hutan. Sayangnya, capaian di atas tidak disebutkan secara rinci berasal dari objek yang mana, apakah semuanya dari program PPTKH atau tanah pelepasan kawasan hutan yang sudah dikeluarkan dan belum diredistribusikan

1 Penyelesaian Penguasaan Tanah dalam Kawasan Hutan (PPTKH) dibentuk berdasarkan Perpres No. 88 Tahun 2017, sedangkan Gugus Tugas Reforma Agraria (GTRA) dibentuk dengan Perpres No. 86 Tahun 2018. Dua perpres ini di bawah dua kementerian berbeda (KLHK dan Kementerian ATR/BPN), namun memiliki tujuan yang sama yakni untuk menyelesaikan persoalan RA di Indonesia. 
sebelum keluarnya Perpres No. 88 Tahun 2017. Beberapa kabupaten melakukan redistribusi dengan objek pelepasan kawasan hutan namun bukan merupakan program PPTKH, misalnya Kabupaten Hulu Sungai Selatan dan Musi Rawas (Kurniawati, dkk., 2020, Dempo, dkk., 2021).

Berangkat dari argumen di atas, studi ini ingin menjelaskan problem objek TORA dari kawasan hutan yang dianggap cukup penting (KLHK, 2018a), walaupun hilirnya dikerjakan oleh Kementerian ATR/BPN, akan tetapi proses dan penyediaan data awalnya berbeda. Pertama, perubahan batas kawasan hutan (berasal dari kawasan hutan produksi atau kawasan hutan lindung yang telah dikuasai, dimiliki, digunakan dan dimanfaatkan untuk permukiman, fasilitas umum dan/atau fasilitas sosial, serta lahan garapan) diselesaikan dengan skema PPTKH (Salim, dkk., 2019), melalui mekanisme inver PTKH untuk melepaskan objeknya dari kawasan hutan (menggunakan Perpres No. 88 Tahun 2017 dan aturan turunannya), kedua, pelepasan kawasan hutan dengan mekanisme perubahan peruntukan kawasan HPK non produktif menjadi bukan kawasan hutan yang diawali dengan penelitian oleh Tim Terpadu.

\section{B. Pendekatan}

Tulisan ini akan menyoroti temuan lapangan yang penulis lakukan selama tiga tahun terakhir dalam format Policy Forum khususnya kebijakan RA dengan objek pelepasan kawasan hutan. Penulis membuat pemetaan persoalan dan menarik kesimpulan berdasarkan temuan data di beberapa daerah serta menawarkan beberapa usulan skema penyelesaian agar praktik kebijakan RA pelepasan kawasan hutan bisa dijalankan dengan efektif dan berkeadilan.

Studi ini telah dilakukan secara kualitatif dan melakukan review tiga tahun laporan observasi lapangan (2018-2020). Kajian bermaksud membaca dan menganalisis hasil studi tersebut untuk menarik benang merah dari kajian RA pelepasan kawasan hutan, khususnya terkait kepemimpinan, kelembagaan, regulasi, dan objek TORA. Empat persoalan tersebut didekati dengan kerangka yang dibangun oleh Borras dan Franco, yakni Kebijakan Pertanahan yang berpihak pada kelompok miskin dengan menerapkan kebijakan administratif pertanahan yang efisien, yang mengarah pada tata kelola pertanahan yang efektif (Borras \& Franco, 2010). Kerangka Borras dan Franco bisa terlihat dalam usulan kebijakan dengan tujuan mengefektifkan sistem dan tata kelola pertanahan dengan sasaran pemerintah sebagai pemegang kebijakan.

\section{Lambatnya Capaian RA Kawasan Hutan: Akar Persoalan dan Perdebatan}

Selama ini, pelepasan kawasan hutan dilakukan dengan menggunakan peraturan Menteri LHK P.27/ Menhut-II/2014 juncto Peraturan Menteri Lingkungan Hidup dan Kehutanan Nomor P.51/MenLHK/ Setjen/Kum.1/6/2016 serta P.44/Menhut-II/2012 juncto P.62/Menhut-II/2013 dan Peraturan Menteri Lingkungan Hidup dan Kehutanan Nomor P.93/Menlhk/Setjen/Kum.1/12/2016. Penulis menduga bahwa capaian redistribusi pelepasan kawasan hutan di atas sebesar 5,15\% campuran antara program PPTKH dan non PPTKH yang sudah diproses untuk dilepaskan sebelum Perpres No. 88 Tahun 2017 dikeluarkan, karena untuk objek TORA dari program PPTKH sampai awal tahun 2020 baru sebatas SK perubahan tata batas, belum sampai di tingkat tapak. Idealnya setelah SK tersebut terbit Kementerian ATR/BPN langsung membentuk panitia redistribusi, namun dalam beberapa kasus masih terdapat keraguan karena tidak dilampiri Berita Acara Perubahan Tata Batas, sehingga di lapangan banyak kabupaten yang masih saling menunggu untuk meredistribusikan kepada masyarakat.

Temuan penulis di lapangan, ada tingkat kerumitan tersendiri di dalam mengurai persoalan objek yang bersumber dari kawasan hutan (PPTKH), selain rumit dalam level koordinasi antarsektor juga rumit dalam hal tata kelola pelepasan kawasan hutan untuk objek TORA. Di lapangan, tata kelola redistribusi tanah hasil pelepasan kawasan hutan sangat problematis dan masih terjadi perdebatan, salah satunya terkait regulasi yang belum clear aturan turunan dari Perpres No. 86/2018 (Utami, dkk., 2019). Perpres 
88 Tahun 2017 hanya mengatur inventarisasi dengan tujuan menentukan objek dan subjek, sementara skema redistribusi hak milik menggunakan Perpres 86 Tahun 2018.

Kementerian Lingkungan Hidupdan Kehutanan(KLHK) beberapa kali memintapertanggungjawaban Kementerian ATR/BPN terkait redistribusi tanah dari lahan kawasan hutan yang sudah dicadangkan sejumlah lebih dari 1 juta hektar (KLHK, 2018b). Akan tetapi, persoalan tersebut tidak dapat dijawab secara lugas oleh Kementerian ATR/BPN dikarenakan beberapa persoalan di lapangan, khususnya dalam hal pemahaman regulasi di tingkat tapak yang berbeda-beda, kesulitan koordinasi antarsektor serta kesulitan penentuan subjek dan objek. Dalam hal objek, seringkali terjadi perdebatan karena klaim KLHK sudah melepaskan kawasan hutan untuk RA, namun tidak ditindaklanjuti oleh Kementerian ATR/BPN. Di sisi lain, terdapat kerumitan atas panjangnya jalur tata cara pelepasan kawasan hutan serta kekaburan lain akibat mempertahankan argumen sektoral masing-masing (Rachman, 2017). Faktanya, hal tersebut memperburuk situasi di lapangan dan berdampak pada lambatnya capaian redistribusi lahan di bagian hilir yang menjadi kewenangan Kementerian ATR/BPN.

Analisis dan pemetaan penulis dalam tiga tahun terakhir di beberapa daerah memperlihatkan bahwa praktik kebijakan RA dari pelepasan kawasan hutan mengalami beberapa persoalan (Utami, dkk., 2018, Salim, dkk., 2018, Salim, dkk., 2019, Salim, dkk., 2020, Ekawati, dkk., 2020). Sedikitnya empat masalah utama yang teridentifikasi ikut menyumbang lambatnya praktik kebijakan RA di daerah: kepemimpinan, kelembagaan, regulasi, dan objek TORA. Penulis akan mencoba menjelaskan empat isu pokok tersebut yang menjadi perdebatan di lapangan untuk memudahkan pemetaan persoalan. Penjelasan berikut didasarkan pada temuan lapangan dalam kurun tiga tahun terakhir sejak 2018 hingga 2020.

\section{Problem Kepemimpinan}

Kunci untuk menjalankan kebijakan RA (khususnya PPTKH) adalah kepemimpinan yang kuat karena ia harus melakukan koordinasi lintas sektor. Komitmen pimpinan dan political will atau kehendak bersama menjalankan program RA harus menjadi agenda bersama, bukan slogan semata. Dalam Perpres No. 88 Tahun 2017, secara formal Tim Percepatan PPTKH dan GTRA langsung dipimpin oleh Menteri Koordinator Bidang Perekonomian, sebagai ketua Deputi Bidang Koordinasi Pengelolaan Energi, Sumberdaya Alam, dan Lingkungan Hidup Kementerian Koordinator Bidang Perekonomian untuk PPTKH dan Menteri ATR/BPN untuk GTRA. Pimpinan level elite (pusat) sifatnya koordinasi, pekerjaan real ada di level provinsi dan kabupaten/kota. Di provinsi PPTKH secara formal dipimpin oleh Kepala Dinas Kehutanan, namun praktiknya pelaksana program di lapangan dikerjakan oleh Kepala Balai Pemantapan Kawasan Hutan (BPKH) sementara GTRA dipimpin oleh gubernur di provinsi dan bupati/walikota di kabupaten/kota, dan ketua hariannya dijalankan oleh Kapala Kantor Wilayah BPN di tingkat provinsi dan Kepala Kantor Pertanahan di tingkat kabupaten/kota.

Persoalannya, leading sector untuk melakukan koordinasi pelaksanaan RA di level daerah sangat lemah, karena di samping tidak memiliki kantor/sekretariat bersama sebagai tempat untuk melakukan koordinasi, juga tidak ada koordinasi intensif dari semua unsur kelembagaan yang menjadi pengelola PPTKH dan GTRA. Di level kabupaten, Kepala Kantor Pertanahan sebagai ketua pelaksana harian lebih memerankan sebagai pejabat administrasi, tidak memiliki keberanian untuk melakukan hal-hal strategis, sebab kewenangannya memang tidak cukup kuat, hal yang sama juga terjadi di level provinsi. Temuan penulis di lapangan menunjukkan, hampir semua kerja-kerja PPTKH dilakukan oleh BPKH, dan pelibatan sektor lain cukup minimal, sementara GTRA yang bertugas untuk melakukan koordinasi juga tidak berjalan dengan baik. Tentu saja di beberapa daerah telah berjalan dengan baik dalam hal koordinasi antar sektor, termasuk rapat bersama telah beberapa kali dilakukan, akan tetapi jika dilihat dari target dan capaian yang diharapkan, upaya itu masih dianggap kecil untuk mewujudkan agenda besar tersebut. 
Secara formal, jabatan GTRA dipegang oleh gubernur dan bupati, hemat penulis sangat tidak efektif, karena pimpinan daerah adalah jabatan strategis, memiliki beban dan pekerjaan yang besar untuk dijalankan. Idealnya gubernur dan bupati harus menunjuk atau menetapkan secara resmi asisten daerah atau wakil lain yang ditunjuk untuk melakukan koordinasi secara rutin dengan stakeholder lainnya. Gubernur dan bupati cukup membuat kebijakan strategisnya sambil menerima laporan rutin setiap hal-hal krusial yang dikerjakan oleh GTRA. Langkah ini akan lebih efektif jika dilakukan oleh pimpinan PPTKH dan GTRA di daerah untuk saling bekerja sama dalam menjalankan programnya, karena kedua program tersebut secara real ada di level tapak. Sejauh ini, peran pucuk pimpinan GTRA dan PPTKH di level daerah belum menonjol dalam memimpin jalannya program kebijakan RA.

Pimpinan GTRA dan PPTKH di daerah harus menjalankan amanat Perpres No. 88 Tahun 2017 dan Perpres No. 86 Tahun 2018, karena esensi dari tugas RA melekat pada pimpinan daerah dengan dukungan stakeholder lainnya. Secara filosofis tanggung jawab RA di daerah milik keduanya karena sebenarnya pemerintah daerah lah yang memiliki subjek dan objek RA di daerah. Secara lebih rinci problem temuan di lapangan beserta simpulan dan solusi penulis gambarkan pada Tabel 1.

Tabel 1. Problem Kepemimpinan dalam Pelaksanaan Kebijakan Reforma Agraria pada Objek Pelepasan Kawasan Hutan

\begin{tabular}{|c|c|c|c|}
\hline No & $\begin{array}{l}\text { Identifikasi Problem } \\
\text { Makro di Lapangan }\end{array}$ & Temuan Praktik Kebijakan Reforma Agraria & $\begin{array}{c}\text { Kesimpulan } \\
\text { dan Penyelesaian }\end{array}$ \\
\hline \multicolumn{4}{|c|}{ Problem Kepemimpinan } \\
\hline 1 & $\begin{array}{l}\text { Komitmen dan political } \\
\text { will semua stakeholder } \\
\text { yang "diragukan" }\end{array}$ & $\begin{array}{l}\text { 1. Komitmen elite politik dan birokrasi } \\
\text { terutama pemda tidak bisa terbaca dengan } \\
\text { jelas sebagai bentuk dedikasi dan kewajiban } \\
\text { yang mengikat untuk menjalankan program } \\
\text { RA secara bersama-sama. } \\
\text { 2. Pemangku kebijakan belum mampu } \\
\text { menyinergikan stakeholder terkait sampai } \\
\text { pada level tapak. Padahal RA di kawasan } \\
\text { hutan dilaksanakan secara lintas sektor } \\
\text { dengan argumen sektoral yang berbeda- } \\
\text { beda sehingga membutuhkan solusi terkait } \\
\text { pola penerapan kebijakan, fasilitasi, alokasi } \\
\text { anggaran dan SDM. } \\
\text { 3. Belum adanya leader sebagai pemangku } \\
\text { kepentingan yang memberikan arahan } \\
\text { satu komando untuk kerja-kerja teknis di } \\
\text { lapangan. } \\
\text { 4. Belum adanya aktor pengganti sebagai } \\
\text { penggerak yang memegang kontrol pada } \\
\text { tatanan praktik di lapangan. } \\
\text { 5evel elite politik belum secara menyeluruh } \\
\text { menyentuh masyarakat. Padahal elite } \\
\text { politik memiliki power tersendiri sehingga } \\
\text { masyarakat akan lebih tergugah untuk } \\
\text { berperan aktif. }\end{array}$ & $\begin{array}{l}\text { Dalam Perpres No. } 86 \text { Tahun 2018, } \\
\text { leading sector RA ada pada gubernur } \\
\text { dan bupati, karena keduanyalah yang } \\
\text { memiliki subjek-objek RA di daerah, } \\
\text { oleh karena itu perlu didudukkan } \\
\text { kembali terkait peran keduanya sebagai } \\
\text { pimpinan di daerah untuk mengelola } \\
\text { RA dengan dukungan lintas sektor. } \\
\text { Gubernur dan bupati harus menunjuk } \\
\text { pimpinan pejabat di pemda sebagai } \\
\text { perpanjangan tangan pemda untuk } \\
\text { melakukan kordinasi } \\
\text { dan mengorganisir GTRA \& PPTKH } \\
\text { di daerah. Koordinasi kepala kantor } \\
\text { pertanahan sebagai pelaksana harian } \\
\text { dengan stakholder lainnya belum } \\
\text { dilaksanakan dengan maksimal dan } \\
\text { terkesan kurang aktif sehingga belum } \\
\text { berhasil menggerakkan anggota } \\
\text { timnya. Kepala kantor harus aktif untuk } \\
\text { memainkan program strategis tersebut. }\end{array}$ \\
\hline 2 & $\begin{array}{l}\text { Peran GTRA dan belum } \\
\text { adanya keyactors atau } \\
\text { tokoh kunci pemegang } \\
\text { kebijakan RA di daerah: } \\
\text { Lemahnya koordinasi } \\
\text { dan tidak adanya } \\
\text { sekretariat bersama }\end{array}$ & $\begin{array}{l}\text { Seharusnya yang menjadi komandan RA di } \\
\text { lapangan dalam menjalankan kebijakan RA } \\
\text { adalah Ketua Tim Inver PTKH (Kepala Dinas } \\
\text { Kehutanan) dan Ketua GTRA (gubernur } \\
\text { dan bupati). Keduanya belum memerankan } \\
\text { perannya sesuai peraturan dan ketiadaan } \\
\text { kantor bersama atau sekretariat di tiap } \\
\text { daerah. Kantor bersama hemat penulis sangat } \\
\text { dibutuhkan. }\end{array}$ & $\begin{array}{l}\text { Ketua GTRA harus mengembalikan } \\
\text { pesan Perpres No. } 88 \text { Tahun } 2017 \text { dan } \\
\text { Perpres No. } 86 \text { Tahun 2018, karena } \\
\text { RA sesungguhya menjadi tugas pokok } \\
\text { pemda dan stakeholder lainnya menjadi } \\
\text { pendukung utama. Kebijakan apapun } \\
\text { yang dilakukan secara parsial tidak akan } \\
\text { menguntungkan masyarakat. Pemda } \\
\text { setempat bersama Kementerian ATR/ } \\
\text { BPN dan KLHK menjadi keyactors. }\end{array}$ \\
\hline
\end{tabular}

Sumber: Data observasi lapangan, 2018-2020. 


\section{Problem Kelembagaan}

Pasca diterbitkannya Perpres No. 88 Tahun 2017 dan Perpres No. 86 Tahun 2018 kemudian berhasil dibentuk lembaga yang bertanggung jawab mengelola persoalan RA yakni Tim Percepatan PTKH dan GTRA. Kedua lembaga ini memiliki misi yang sama yakni menjalankan RA, melakukan inventarisasi objek-subjek, dan terakhir melakukan redistribusi. Khusus PPTKH mandat yang diberikan adalah melakukan identifikasi lahan-lahan masyarakat dalam kawasan hutan yang ujungnya jika memenuhi persyaratan akan dikeluarkan dari kawasan hutan, kemudian diredistribusikan kepada masyarakat yang menguasai sesuai persyaratan atau menggunakan skema Perhutanan Sosial (Siscawati, dkk., 2017).

Sejauhapa kedua lembaga ini memerankan mandatnyadalam konteks redistribusi tanah dan penataan aset dan akses? Problem keduanya masih sama yakni akselerasi yang lamban dalam menyelesaikan berbagai persoalan, akibat tingkat kerumitan dan jalan panjang penyelesaian lahan masyarakat dalam kawasan hutan. Yang menjadi problem di lapangan dan sering dijumpai adalah aktor kunci dalam mengelola organisasi yang tidak secara tegas memainkan perannya, kemudian persoalan data khususnya objek dan subjek, masing-masing stakeholder tidak secara terbuka atau transparan berbagi data untuk mempermudah kerja-kerja di lapangan, minimnya anggaran termasuk pemda belum secara aktif terlibat atau melibatkan anggarannyaa untuk pengelolaan RA, sumber daya manusia di lapangan yang terbatas, dan sosialisasi program di level tapak yang terbatas, sehingga banyak masyarakat yang tidak memahami program strategis pemerintah. Tabel 2 akan menjelaskan problem riil di lapangan yang penulis himpun untuk memudahkan pemetaan persoalan.

Tabel 2. Problem Kelembagaan dalam Pelaksanaan Kebijakan Reforma Agraria pada Objek Pelepasan Kawasan Hutan

\begin{tabular}{|c|c|c|c|}
\hline No & $\begin{array}{l}\text { Identifikasi Problem } \\
\text { Makro di Lapangan }\end{array}$ & Temuan Praktik Kebijakan Reforma Agraria & Kesimpulan \\
\hline \multicolumn{4}{|c|}{ Problem Kelembagaan } \\
\hline 1 & $\begin{array}{l}\text { Koordinasi antar } \\
\text { lembaga, khususnya Tim } \\
\text { Inver PTKH }\end{array}$ & $\begin{array}{l}\text { Temuan di lapangan seringkali justru } \\
\text { menunjukkan gap antar stakeholder, yakni } \\
\text { terkait anggaran dan koordinasi, salah satunya } \\
\text { faktor sekretariat bersama yang tidak ada. } \\
\text { Misalnya, dalam inver PPTKH, Kementerian } \\
\text { ATR/BPN semestinya menjadi sekretaris, } \\
\text { namun semua kendali dipegang oleh BPKH. } \\
\text { Hal ini karena BPKH merasa anggaran } \\
\text { kegiatannya ada di lembaganya, begitu juga } \\
\text { anggaran GTRA ada di Kementerian ATR/BPN, } \\
\text { sementara pemda merasa bukan pekerjaannya. } \\
\text { Realitas ini ditemukan di banyak daerah, } \\
\text { khususnya kabupaten/kota. }\end{array}$ & $\begin{array}{l}\text { Perlu membentuk kantor bersama } \\
\text { untuk menjalankan kebijakan RA, } \\
\text { minimal di level provinsi, agar masing- } \\
\text { masing stakeholder merasa memiliki } \\
\text { tanggung jawab bersama. Selain itu, } \\
\text { perlu dilakukan centering anggaran, } \\
\text { cukup dalam satu tempat, di pemda } \\
\text { atau di Kemenko, agar kontrol } \\
\text { pelaksanaan kegiatannya lebih mudah. } \\
\text { Menko sebagai pimpinan utama ikut } \\
\text { bertanggung jawab dan mengontrol } \\
\text { jalannya kebijakan. }\end{array}$ \\
\hline 2 & $\begin{array}{l}\text { Problem SDM yang } \\
\text { tidak memadai dan } \\
\text { mencukupi di semua } \\
\text { sektor pendukung } \\
\text { pelaksanaan RA, } \\
\text { termasuk keterlibatan } \\
\text { stakeholder dalam } \\
\text { menjalankan Inver } \\
\text { PTKH }\end{array}$ & $\begin{array}{l}\text { Prioritas kebijakan Kementerian ATR/BPN sejak } \\
2017 \text { adalah PTSL. Tahun } 2018 \text { muncul kebijakan } \\
\text { PPTKH dan kendala SDM dari Kementerian } \\
\text { ATR/BPN mulai dirasakan. Imbasnya, kerja } \\
\text { lintas sektor untuk Inver PTKH tidak bisa } \\
\text { dibangun dengan maksimal. Konsekuensinya, } \\
\text { Tim Inver PTKH tidak maksimal membantu } \\
\text { masyarakat dalam mengusulkan lahan-lahannya } \\
\text { untuk dikeluarkan dari kawasan hutan, } \\
\text { sekalipun menurut Perpres No. } 88 \text { Tahun } 2017 \\
\text { usulan harus dari masyarakat, namun kendala } \\
\text { sosialisasi dan capacity building masyarakat } \\
\text { menjadi isu utama, dan banyak desa tidak } \\
\text { mengusulkan karena tidak cukup mendapat } \\
\text { informasi dan memahami persoalan PPTKH. } \\
\text { Mekanisme jemput bola hanya sedikit yang }\end{array}$ & $\begin{array}{l}\text { Idealnya, semua stakeholder terkait ikut } \\
\text { terlibat dalam proses identifikasi dan } \\
\text { pengerjaan projek RA di lapangan. SDM } \\
\text { seharusnya menjadi tanggung jawab } \\
\text { ketiga lembaga, KLHK, Kementerian } \\
\text { ATR/BPN, dan Pemda. Selama ini pemda } \\
\text { belum terlibat aktif untuk urusan SDM } \\
\text { dan Kementerian ATR/BPN juga masih } \\
\text { terbatas melibatkan SDM-nya untuk } \\
\text { program PPTKH (RA pencadangan dan } \\
\text { pelepasan kawasan hutan). Solusinya, } \\
\text { GTRA menjadi leading sector pada } \\
\text { isu tersebut dan memastikan semua } \\
\text { stakeholder sepakat secara bersama- } \\
\text { sama menyelesaikannya, bukan hanya } \\
\text { menjadi tanggung jawab KLHK (BPKH). }\end{array}$ \\
\hline
\end{tabular}




\begin{tabular}{|c|c|c|c|}
\hline No & $\begin{array}{l}\text { Identifikasi Problem } \\
\text { Makro di Lapangan }\end{array}$ & Temuan Praktik Kebijakan Reforma Agraria & Kesimpulan \\
\hline & & $\begin{array}{l}\text { bisa dilakukan karena keterbatasan SDM untuk } \\
\text { mengerjakannya. Kurangnya sosialisasi dan } \\
\text { capacity building masyarakat menjadi salah satu } \\
\text { penyebab banyak lahan yang diusulkan berakhir } \\
\text { pada rekomendasi Perhutanan Sosial, padahal } \\
\text { beberapa lahan layak untuk direkomendasikan } \\
\text { menjadi Hak Milik sesuai peraturan. }\end{array}$ & $\begin{array}{l}\text { Ke depan, penyatuan program ini dalam } \\
\text { satu pintu akan jauh lebih memudahkan } \\
\text { penyelesaian persoalan. }\end{array}$ \\
\hline 3 & $\begin{array}{l}\text { Transparansi dalam } \\
\text { hal persoalan data } \\
\text { sebagai basis kebijakan } \\
\text { dan analisis persoalan } \\
\text { (database objek/subjek) }\end{array}$ & $\begin{array}{l}\text { Semua stakeholder belum mau secara } \\
\text { terbuka share data (open resources) untuk } \\
\text { mempermudah pemetaan kerja khususnya } \\
\text { antara Kementerian ATR/BPN dan KLHK- } \\
\text { BPKH. Untuk itu perlu kebijakan satu pintu } \\
\text { dalam menangani persoalan RA untuk } \\
\text { mempermudah dalam menjalankan kebijakan } \\
\text { RA di lapangan. }\end{array}$ & $\begin{array}{l}\text { Seharusnya, hal ini diperankan oleh } \\
\text { Ketua GTRA dan Ketua Tim Inver PTKH } \\
\text { pusat (Menko Perekonomian). Idealnya, } \\
\text { di bawah satu komando bisa diciptakan } \\
\text { satu basis data untuk memudahkan } \\
\text { pelaksanaan RA di level bawah, agar } \\
\text { tumpang tindih dan saling silang serta } \\
\text { ego sektoral bisa diminimalisir, kata } \\
\text { kuncinya open resources database yang } \\
\text { digunakan secara "bagi pakai" oleh } \\
\text { instansi pusat dan/atau pemerintah } \\
\text { daerah untuk kepentingan RA di } \\
\text { kawasan hutan juga non hutan. }\end{array}$ \\
\hline 4 & $\begin{array}{l}\text { Minimnya anggaran, } \\
\text { belum bisa } \\
\text { memanfaatkan potensi } \\
\text { anggaran dari pemda } \\
\text { sesuai perpres yang ada. }\end{array}$ & $\begin{array}{l}\text { Ketersediaan anggaran di Kementerian ATR/ } \\
\text { BPN dan KLHK masih terbatas, belum berhasil } \\
\text { melibatkan seluruh stakeholder untuk sharing } \\
\text { anggaran untuk menjalankan semua program } \\
\text { RA termasuk dalam pembentukan GTRA di } \\
\text { daerah, khususnya di tingkat kabupaten/kota. }\end{array}$ & $\begin{array}{l}\text { RA sebagai program strategis nasional } \\
\text { dan menjadi tanggung jawab pemerintah } \\
\text { dari pusat sampai daerah seharusnya } \\
\text { menjadikan kesadaran bersama bahwa } \\
\text { penganggaran untuk kegiatan dilakukan } \\
\text { secara bersama-sama, termasuk di } \\
\text { level pemda/kabupaten-kota (sharing } \\
\text { anggaran). }\end{array}$ \\
\hline 5 & $\begin{array}{l}\text { Sosialisasi yang tidak } \\
\text { sampai sasaran atau } \\
\text { tidak efekif dalam } \\
\text { menyampaikan program } \\
\text { strategis nasional } \\
\text { pada level daerah } \\
\text { dan masyarakat desa } \\
\text { yang potensial sebagai } \\
\text { penerima/subjek }\end{array}$ & $\begin{array}{l}\text { Temuan data lapangan menunjukkan, terjadi } \\
\text { persoalan siapa yang harus berperan menjadi } \\
\text { keyperson untuk menyampaikan sosialisasi } \\
\text { kepada masyarakat di berbagai level. Tidak } \\
\text { harus selalu pimpinan masing-masing } \\
\text { lembaga untuk menyampaikan informasi } \\
\text { secara cepat kepada semua stakeholder dan } \\
\text { masyarakat, namun butuh kerja sama dan } \\
\text { kesepakatan siapa yang harus memerankannya } \\
\text { termasuk pemanfaatan media apa untuk } \\
\text { menyampaikannya. Program PPTKH di } \\
\text { kabupaten/kota mengalami kendala di } \\
\text { lapangan karena masyarakat minim informasi. } \\
\text { Masyarakat desa tidak mengajukan kepada } \\
\text { Tim Inver PTKH karena banyak yang tidak } \\
\text { memahami program tersebut. }\end{array}$ & $\begin{array}{l}\text { Idealnya, mengefektifkan peran GTRA } \\
\text { (gubernur dan bupati perlu menunjuk } \\
\text { pejabat bawahannya) sebagai leading } \\
\text { sektor di daerah agar komunikasi } \\
\text { antarsektor dan sosialisasi efektif, karena } \\
\text { pemda memiliki SDM lengkap sampai } \\
\text { level desa, sehingga bisa dimanfaatkan } \\
\text { untuk memerankan misi tersebut yakni } \\
\text { sosialisasi program strategis RA. }\end{array}$ \\
\hline
\end{tabular}

Sumber: Data observasi lapangan, 2018-2020.

\section{Problem Regulasi}

Awalnya, dua peraturan presiden yang dikeluarkan oleh pemerintah terkait RA akan memudahkan dalam menjalankan program di masing-masing kementerian. Faktanya, seiring perjalanan dua regulasi tersebut saling terkait, karena hilir dari Perpres No. 88 Tahun 2017 adalah redistribusi yang diatur dalam perpres 86/2018. Di lapangan, ego masing-masing justru kelihatan di dalam mengatur program RA. Bagi KLHK yang membidangi PPTKH, sebagian daerah sangat terlihat dikerjakan sendiri dan tidak banyak melibatkan stakeholder lainnya. Kementerian ATR/BPN menganggap sebagian besar PPTKH adalah pekerjaan KLHK, sebaliknya GTRA dan redistribusi merupakan domain Kementerian ATR/BPN. Argumen tersebut menegaskan bahwa masing-masing kementerian bekerja namun secara sendirisendiri, tidak bekerja secara bersama-sama. Idealnya, dua regulasi tersebut digabung menjadi satu dan 
dikerjakan secara bersama-sama oleh dua kementerian terkait dan didukung oleh stakeholder lainnya, namun faktanya tidak demikian.

Persoalan lain yang krusial adalah alur birokrasi di dalam proses pelepasan kawasan hutan. Dua lembaga pokok yang mengelola RA kawasan hutan tidak pernah duduk bersama untuk menyepakati cara yang efektif untuk melepaskan kawasan hutan sebagai objek TORA. Hal itu penting dilakukan karena proses dan tatacara pelepasan kawasan hutan alurnya sangat panjang dan tidak mudah. Situasi tersebut menjadi kendala mengapa capaian redistribusi yang objeknya dari kawasan hutan masih sangat rendah. Secara lebih rinci penulis jelaskan dalam skema Tabel 3 untuk memudahkan pemetaan problem yang terjadi di lapangan.

\section{Tabel 3. Problem Regulasi dalam Pelaksanaan Kebijakan Reforma Agraria} pada Objek Pelepasan Kawasan Hutan

\begin{tabular}{|c|c|c|c|}
\hline No & $\begin{array}{l}\text { Identifikasi Problem } \\
\text { Makro di Lapangan }\end{array}$ & Temuan Praktik Kebijakan Reforma Agraria & Kesimpulan \\
\hline \multicolumn{4}{|c|}{ Problem Regulasi } \\
\hline 1 & $\begin{array}{l}\text { Munculnya dua regulasi } \\
\text { yang mengatur satu isu } \\
\text { (RA) justru membuat } \\
\text { tidak efektif dan } \\
\text { tumpang tindih pada } \\
\text { tataran kelembagaan } \\
\text { maupun tata kelolanya }\end{array}$ & $\begin{array}{l}\text { 1. Kedua regulasi tersebut belum mampu } \\
\text { menyinkronkan pengaturan dan tata } \\
\text { kelola RA khususnya RA di kawasan hutan } \\
\text { bahkan terkesan tumpang tindih. Sehingga } \\
\text { beberapa kebijakan justru ditafsirkan } \\
\text { secara bias oleh masing-masing pemangku } \\
\text { kepentingan dengan mengedepankan } \\
\text { argumen sektoral masing-masing. } \\
\text { 2. PPTKH yang dijalankan melalui dua } \\
\text { regulasi oleh lintas sektor justru } \\
\text { menimbulkan multitafsir karena tiap sektor } \\
\text { membawa pemahamannya masing-masing } \\
\text { dalam mengimplementasikan kebijakan } \\
\text { tersebut. Sehingga sulit untuk menyamakan } \\
\text { suara terkait beberapa pemahaman yang } \\
\text { krusial, misalnya persamaan persepsi objek } \\
\text { TORA. } \\
\text { 3. } \\
\text { daerah, sehingga pembelahan kebijakan } \\
\text { terlihat dan kompromi sulit dicapai oleh } \\
\text { kedua lembaga, karena masing-masing } \\
\text { bekerja secara sektoral (Kementerian ATR/ } \\
\text { BPN vs KLHK). }\end{array}$ & $\begin{array}{l}\text { Presiden perlu menata ulang dua Perpres } \\
\text { yang sejatinya memiliki niat baik yang } \\
\text { sama. Dalam jangka menengah, penulis } \\
\text { menyarankan perlu dilakukan review } \\
\text { untuk menyatukan kedua perpres } \\
\text { tersebut, bahkan jika diperlukan diatur } \\
\text { dalam satu peraturan, apakah inti } \\
\text { pokoknya dimasukkan dalam RUU } \\
\text { Pertanahan (jika masih dibahas di DPR) } \\
\text { kemudian dibuat aturan teknisnya, } \\
\text { atau dua perpres (88/2017 dan } 86 / 2018) \\
\text { dijadikan satu. }\end{array}$ \\
\hline 2 & $\begin{array}{l}\text { Alur birokrasi yang } \\
\text { bersumber dari } \\
\text { regulasi KLHK menjadi } \\
\text { kendala capaian RA. } \\
\text { Objek TORA dari } \\
\text { pelepasan kawasan } \\
\text { hutan bersumber dari } \\
\text { Peraturan Menteri } \\
\text { KLHK P. 42/2019 } \\
\text { tentang Tata Cara } \\
\text { Pelepasan Kawasan } \\
\text { Hutan dan Perubahan } \\
\text { Batas Kawasan Hutan } \\
\text { untuk Sumber Tanah } \\
\text { Obyek Reforma Agraria. }\end{array}$ & $\begin{array}{l}\text { Di lapangan kinerja pemda tampak tidak efektif } \\
\text { dalam mengelola tanah yang dicadangkan dari } \\
\text { kawasan hutan, karena banyak pemda tidak } \\
\text { mengusulkan kepada KLHK atas tanah-tanah } \\
\text { yang sudah dicadangkan oleh KLHK untuk } \\
\text { TORA, padahal untuk mengeluarkannya } \\
\text { perlu usulan dari pemda sesuai aturan No. } \\
\text { P.42/2019. Di lapangan banyak penulis temukan } \\
\text { tanah-tanah yang sudah dicadangkan untuk } \\
\text { objek TORA mangkrak, karena pemda tidak } \\
\text { mengusulkan proyeksi pemanfaatannya, dan } \\
\text { masyarakat dimungkinkan secara berkelompok } \\
\text { maupun mandiri mengajukan, namun warga } \\
\text { tidak memahami persoalan tersebut (nir } \\
\text { sosialisasi). }\end{array}$ & $\begin{array}{l}\text { Pelu melakukan review dengan tujuan } \\
\text { merevisi P. 42/2019 yang alurnya cukup } \\
\text { panjang, karena harus melewati Tim } \\
\text { Terpadu (Timdu) dan pencadangan. } \\
\text { Proses ini menghambat karena } \\
\text { sebenarnya HPK sudah diidentifikasi } \\
\text { awal sehingga masuk Peta Indikatif (PI) } \\
\text { TORA. Seharusnya dari PI sudah bisa } \\
\text { dilakukan verifikasi bersama di lapangan } \\
\text { dan langsung rekomendasi, tidak harus } \\
\text { melewati Timdu dan pencadangan. } \\
\text { Tata batas di lapangan cukup dilakukan } \\
\text { di level provinsi, karena daerah yang } \\
\text { memahami wilayahnya termasuk } \\
\text { kebutuhan untuk warganya. }\end{array}$ \\
\hline
\end{tabular}




\begin{tabular}{|c|c|c|c|}
\hline No & $\begin{array}{l}\text { Identifikasi Problem } \\
\text { Makro di Lapangan }\end{array}$ & Temuan Praktik Kebijakan Reforma Agraria & Kesimpulan \\
\hline 3 & $\begin{array}{l}\text { Alur birokrasi pelepasan } \\
\text { kawasan hutan untuk } \\
\text { objek PPTKH (Perpres } \\
\text { No. } 88 \text { Tahun } 2017 \text { dan } \\
\text { aturan turunannya } \\
\text { Permenko No. } 3 \text { Tahun } \\
\text { 2018) terlalu panjang. }\end{array}$ & $\begin{array}{l}\text { Perpres No. } 88 \text { Tahun } 2017 \text { dan Permenko } \\
\text { No. } 3 \text { Tahun } 2018 \text { memiliki jalur penyelesaian } \\
\text { yang panjang. Berdasarkan pengalaman } \\
\text { lapangan, sejak proses sosialisasi, pengusulan } \\
\text { melalui beberapa tahap, dari desa, kabupaten, } \\
\text { dan provinsi, setelah itu turun Tim Inver } \\
\text { PTKH melakukan verifikasi, selanjutnya } \\
\text { naik ke provinsi pada tahap pembahasan dan } \\
\text { rekomendasi. Hasil rekomendasi Tim Inver } \\
\text { PTKH (provinsi) kemudian dikirim ke pusat } \\
\text { untuk dibahas oleh Tim Percepatan PPTKH } \\
\text { (pusat). Dari pusat kemudian keluar SK tata } \\
\text { batas, baru kemudian ke lapangan untuk cek } \\
\text { data lapangan dan tata batas di lapangan. } \\
\text { Setelah clear, tim kadaster Kementerian } \\
\text { ATR/BPN (Panitia Landreform) melakukan } \\
\text { pengukuran untuk redistribusi. Dengan } \\
\text { jalur birokrasi demikian, tidak heran jika } \\
\text { usulan yang diajukan pada September 2o18, } \\
\text { hingga akhir tahun 202o baru sampai tahap } \\
\text { dikeluarkannya SK Tata Batas dan belum pada } \\
\text { bagian hilir (redistribusi) yang seharusnya } \\
\text { dikerjakan oleh Kementerian ATR/BPN. }\end{array}$ & $\begin{array}{l}\text { Dalam jangka pendek, perlu merevisi } \\
\text { Permenko No. } 3 \text { Tahun } 2018 \text { terkait } \\
\text { alur pelepasan kawasan hutan untuk } \\
\text { PPTKH, menyederhanakan prosesnya } \\
\text { cukup dikerjakan di level provinsi, } \\
\text { pusat hanya menerbitkan SK Tata Batas. } \\
\text { Sementara Tim Inver PTKH turun ke } \\
\text { lapangan harus melibatkan semua } \\
\text { stakeholder, agar efektif Tim inver PTKH } \\
\text { bekerja langsung bersamaan dengan } \\
\text { pengukuran kadaster. Setelah SK Tata } \\
\text { Batas keluar sudah dalam bentuk final, } \\
\text { dikelompokkan mana bidang-bidang } \\
\text { yang akan dikeluarkan dari kawasan } \\
\text { hutan (redistribusi) dan mana yang } \\
\text { masuk skema Perhutanan Sosial. Dengan } \\
\text { begitu, Tim tidak bekerja dua kali turun } \\
\text { lapangan. Rekomendasi hasil Tim inver } \\
\text { PTKH (level kabupaten dan provinsi) } \\
\text { harus menjadi perhatian utama, karena } \\
\text { yang memiliki subjek dan objek sejatinya } \\
\text { adalah pemda, bukan pemerintah pusat. } \\
\text { Pemerintah pusat cukup melakukan } \\
\text { kontrol kebijakan agar tidak menyalahi } \\
\text { peraturan perundang-undangan dan } \\
\text { melampaui batas. }\end{array}$ \\
\hline
\end{tabular}

Sumber: Data observasi lapangan, 2018-2020.

\section{Problem Objek TORA}

Kementerian Lingkungan Hidup dan Kehutanan telah mengeluarkan peraturan terkait objek TORA yang bersumber dari kawasan hutan. Setidaknya KLHK telah menentukan 7 kriteria objek TORA. Akan tetapi, tafsir di lapangan mengalami banyak perbedaan yang sumber persoalan utamanya adalah tafsir terhadap peraturan. Praktik di lapangan di dalam memahami TORA yang bersumber dari kawasan hutan setidaknya terdapat dua model dalam melihat persoalan, pertama terkait pencadangan dan pelepasan. Dua istilah ini dimaknai berbeda oleh Kementerian ATR/BPN, sementara di KLHK tata cara pelepasan kawasan hutan sangat ketat (Salim, dkk., 2019). Tentu ketidaksamaan dalam memahami regulasi ini berpengaruh terhadap cara melihat objek RA, dan ujungnya adalah kemandekan program. Semua persoalan tersebut sebenarnya bisa diselesaikan secara bersama-sama jika kedua kementerian ini menyepakati mana objek TORA pelepasan kawasan hutan yang akan dikeluarkan dan dilakukan redistribusi, agar lebih mudah langkahnya, tidak melewati alur birokrasi yang panjang. Tabel 4 berikut penulis hadirkan untuk memudahkan pembaca dalam melihat persoalan sekaligus bagaimana memahami dan menyelesaikan kemandegan-kemandegan program kebijakan di level tapak. Jika bisa bersepakat dan menemukan titik temu, maka capaian dan jalannya kebijakan RA yang bersumber dari pelepasan kawasan hutan akan jauh lebih mudah dilaksanakan. 
Tabel 4. Problem Objek TORA dalam Pelaksanaan Kebijakan Reforma Agraria pada Objek Pelepasan Kawasan Hutan

\begin{tabular}{|c|c|c|c|}
\hline No & $\begin{array}{l}\text { Identifikasi Problem } \\
\text { Makro di Lapangan }\end{array}$ & $\begin{array}{c}\text { Temuan Praktik Kebijakan } \\
\text { Reforma Agraria }\end{array}$ & Kesimpulan \\
\hline \multicolumn{4}{|c|}{ Problem Objek TORA } \\
\hline 1 & $\begin{array}{l}\text { Perbedaan tafsir dalam } \\
\text { memahami objek } \\
\text { TORA atas } 7 \text { kriteria } \\
\text { yang dikeluarkan oleh } \\
\text { KLHK. }\end{array}$ & $\begin{array}{l}\text { Belum ada kesepakatan dan } \\
\text { satu visi di dalam memahami } \\
\text { TORA pelepasan kawasan hutan, } \\
\text { terutama alokasi 20\% pelepasan } \\
\text { kawasan hutan yang sudah } \\
\text { dikeluarkan. }\end{array}$ & $\begin{array}{l}\text { KLHK, Kementerian ATR/BPN, dan gubernur harus } \\
\text { duduk bersama menyelesaikan objek 20\% kawasan } \\
\text { hutan yang sudah dilepaskan (kriteria I Alokasi } \\
\text { TORA dari 20\% pelepasan kawasan hutan untuk } \\
\text { perkebunan), agar bisa dipastikan di mana letak lahan } \\
\text { yang telah dilepaskan. Di lapangan, hal ini menjadi } \\
\text { persoalan karena pelepasan kawasan hutan yang harus } \\
\text { menyerahkan 20\% lahan untuk masyarakat sekitar } \\
\text { tidak terkontrol oleh ketiga belah pihak (pemda, } \\
\text { Kementerian ATR/BPN, KLHK), sehingga objeknya } \\
\text { tidak bisa dideteksi secara keseluruhan. Karena ini } \\
\text { sudah terjadi, maka menjadi kewajiban pemerintah } \\
\text { pusat untuk menyelesaikannya bersama pemda dan } \\
\text { stakeholder lainnya. }\end{array}$ \\
\hline 2 & $\begin{array}{l}\text { Perbedaan dalam } \\
\text { memahami } \\
\text { pencadangan dan } \\
\text { pelepasan kawasan } \\
\text { hutan. Pemahaman } \\
\text { Kementerian ATR/ } \\
\text { BPN terkait tata cara } \\
\text { memberikan lahan } \\
\text { kepada masyarakat } \\
\text { dari lahan yang } \\
\text { dicadangkan dan } \\
\text { dilepaskan masih } \\
\text { belum sama dengan } \\
\text { KLHK. Hal ini terkait } \\
\text { regulasi sektoral yang } \\
\text { belum dipahami } \\
\text { bersama. }\end{array}$ & $\begin{array}{l}\text { Sejauh ini, KLHK mengklaim } \\
\text { sudah mencadangkan lahan } \\
\text { kawasan hutan untuk objek TORA } \\
\text { lebih dari juta hektar. Bahasa } \\
\text { pencadangan dalam terminologi } \\
\text { KLHK dimaknai berbeda oleh } \\
\text { sebagian warga Kementerian ATR/ } \\
\text { BPN, dan meminta agar istilah } \\
\text { pencadangan langsung menjadi } \\
\text { objek TORA. Dalam aturan } \\
\text { KLHK, pencadangan bukan } \\
\text { berarti pelepasan, melainkan } \\
\text { harus melalui tahapan proses } \\
\text { pengusulan dari masyarakat/ } \\
\text { pemda atau instansi pemerintah } \\
\text { lain sesuai Peraturan Menteri } \\
\text { LHK No. 17/2o18 bahwa proses } \\
\text { pelepasan kawasan hutan } \\
\text { merupakan proses yang harus } \\
\text { melewati beberapa tahap: } \\
\text { penelitian terpadu, pencadangan, } \\
\text { permohonan tata batas dan } \\
\text { penetapan batas, permohonan } \\
\text { pelepasan, dan penerbitan } \\
\text { keputusan pelepasan, dan } \\
\text { penetapan batas oleh Menteri } \\
\text { KLHK. Tahapan ini tidak } \\
\text { dipahami sepenuhnya oleh } \\
\text { sebagian besar warga Kementerian } \\
\text { ATR/BPN, sehingga sering } \\
\text { menjadi persoalan di lapangan, } \\
\text { dan lahan kawasan hutan yang } \\
\text { sudah dicadangkan hingga saat ini } \\
\text { capaiannya masih belum cukup } \\
\text { jelas. }\end{array}$ & $\begin{array}{l}\text { Problem penafsiran menjadi isu utama, karena } \\
\text { KLHK dan Kementerian ATR/BPN berbeda dalam } \\
\text { menafsirkan pencadangan dan pelepasan kawasan } \\
\text { hutan. Dengan duduk bersama dan menunjukkan } \\
\text { data agar tafsir atas peraturannya bisa sama, sehingga } \\
\text { tidak menimbulkan berbagai asumsi di lapangan. Hal } \\
\text { ini bisa diselesaikan jika GTRA di level provinsi duduk } \\
\text { bersama mencari solusi demi kepentingan masyarakat } \\
\text { banyak. }\end{array}$ \\
\hline
\end{tabular}

Sumber: Data observasi lapangan, 2018-2021.

Realitas di atas ikut menyumbang lambatnya pencapaian redistribusi tanah yang bersumber dari kawasan hutan bahkan terkesan jalan di tempat. Sedikitnya dari 4 isu pokok (kepemimpinan, kelembagaan, regulasi, dan objek TORA) penulis perinci dalam 12 pemetaan persoalan sebagai isu sentralnya pada Tabel 1 sampai dengan Tabel 4. Penulis mencoba menguraikan terkait problem di lapangan atas praktik kebijakan RA di kawasan hutan pada level tapak yang menemui beberapa kendala 
teknis, baik persoalan koordinasi, pemahaman, maupun tafsir atas regulasi. Secara kepemimpinan diperlukan sinergi antarsektor, karena salah satu syarat kesuksesan pelaksanaan RA adalah kemauan politik elit penguasa dalam memadukan lintas sektor/kementerian (Luthfi, 2018). Secara kelembagaan harus diperjelas siapakah keyactors beserta wewenangnya dalam pelaksanaan kegiatan sampai pada tataran praktik di lapangan sehingga semua stakeholder menjalankan peran dengan baik. Terbitnya dua perpres dengan satu isu dalam rentang waktu dekat menampakkan kentalnya ego sektoral, selain itu potensi tumpang tindih dalam pengaturan dan tata kelolanya pun semakin meningkat. Tumpang tindih pengaturan dan tata kelola menyebabkan multitafsir pada tingkat tapak, dengan pemahaman regulasi yang berbeda-beda serta koordinasi yang terbatas antarsektor membuat tafsir semakin kabur dan sulit menentuan objek TORA.

Dua belas persoalan tersebut menurut penulis menjadi penyumbang ketidaklancaran praktik kebijakan RA di daerah, tentu saja tanpa menafikan peran semua lembaga telah bekerja keras di lapangan, namun semua itu masih menampakkan ketidakefektifan tata kelola RA. Persoalannya, apakah pemerintah utamanya KLHK, Kementerian ATR/BPN, dan pemda mau duduk bersama untuk mencari solusi bersama karena RA menjadi tanggung jawab utama dari ketiga lembaga ini. Tanpa kesepakatan baru dalam melihat persoalan di lapangan, maka RAakan menjadi barang penting yang "pelan" geraknya, sulit dipercepat sepanjang political will pemerintah terkait kelembagaan dan regulasi, objek-subjek, dan SDM tidak ditata ulang secara bersama-sama. Cara mudah memang tidak harus merubah regulasi, namun membuat beberapa konsensus baru yakni mencari kesepakatan bersama sebagaimana penulis usulkan di atas secara bersama-sama demi mencapai tujuan bersama. Langkah itu perlu diambil karena RA butuh dikerjakan secara bersama-sama untuk menuju goal yang ditetapkan oleh Pemerintahan Presiden Joko Widodo, yakni kepastian aset dan akses untuk meningkatkan kesejahteraan masyarakat. Bagi penulis, kondisi tersebut masih pada level penataan aset, belum bisa melangkah lebih jauh pada penataan akses. Jika persoalan aset saja belum bisa diselesaikan, maka tidak mungkin melangkah terburu-buru untuk membicarakan lebih jauh terkait akses. Redistribusi kawasan non hutan sudah berada pada tahap lanjut yakni penataan akses, namun untuk objek pelepasan kawasan hutan hemat penulis belum sampai pada penataan akses.

\section{Kesimpulan}

Berdasarkan pengalaman kerja di lapangan, menilik berbagai problem yang dijelaskan di atas maka sangat masuk akal jika capaian kinerja Kementerian ATR/BPN dalam hal redistribusi tanah dari objek TORA kawasan hutan sangat lambat. Persoalannya bukan hanya kepemimpinan, kelembagaan, regulasi, dan objek tetapi juga cara kerja yang relatif panjang menuju redistribusi dan political will serta komitmen para pemangku kepentingan untuk menjalankan RA di kawasan hutan yang perlu mendapat perhatian. Di luar itu, pemahaman masing-masing stakeholder di lapangan yang tidak sama menjadi salah satu penyebab mengapa koordinasi antar stakeholder tidak lancar dilakukan.

Terkait hal tersebut, penulis berpendapat bahwa, alur RA di kawasan hutan sebenarnya tidak terlalu rumit untuk dijalankan jika ada cukup kesempatan bagi masing-masing pihak untuk mengurai secara bersama problem di sektor masing-masing. Hal itu penting untuk menyepakati dan memahamkan secara bersama-sama, agar tidak saling meniadakan sektor lain. Jika kerja bersama-sama dengan tujuan yang sama, maka tujuan yang ingin dicapai akan segera terwujud. KLHK, Kementerian ATR/BPN, dan pemda harus lebih solid dalam membangun kerja sama baik di pusat maupun di daerah, serta dibutuhkan dorongan pusat untuk meyakinkan daerah terkait program RA di kawasan hutan sebagai program strategis nasional yang penting untuk diselesaikan. 


\section{E. Rekomendasi}

1. Menko Perekonomian sebagai Pimpinan Pusat GTRA dan Tim Inver PTKH harus mendorong gubernur dan bupati untuk menjalankan secara serius peran keduanya sebagai pimpinan di daerah untuk mengelola RA di kawasan hutan dengan dukungan lintas sektor. Pada level kabupaten, sebaiknya ditunjuk langsung bawahan bupati/walikota (Sekda atau Kepala Dinas Pertanahan) untuk menjalankan roda organisasi, tentunya harus bekerjasama dengan ketua pelaksana harian dari Kepala Kantor Pertanahan.

2. Ketua GTRA dan Ketua Tim Inver PTKH di daerah harus mampu menciptakan satu basis data untuk memudahkan pelaksanaan RA di level bawah, agar tumpang tindih dan saling silang serta ego sektoral bisa diminimalisir, kata kuncinya open resources database yang digunakan secara "bagi pakai" oleh instansi pusat dan/atau pemerintah daerah untuk kepentingan RA di kawasan hutan.

3. Manajemen kebijakan RA satu "pintu" dengan membentuk kantor bersama perlu dikembangkan untuk menjalankan kebijakan RA di kawasan hutan, minimal di level provinsi, agar masing-masing stakeholder merasa memiliki tanggung jawab bersama. Selain itu, perlu dilakukan pemusatan anggaran, cukup dalam satu tempat, apakah di pemda atau di kementerian, agar kontrol pelaksanaan kegiatannya lebih mudah. Menko Bidang Perekonomian sebagai pimpinan utama ikut bertanggung jawab dan mengontrol jalannya kebijakan.

4. Harus ada kesepakatan bersama antara Menko Bidang Perekonomian, Mendagri, Menteri KLHK, dan Menteri ATR/BPN mengenai persoalan penganggaran untuk kegiatan RA di kawasan hutan. Idealnya perencanaan anggaran dilakukan secara bersama-sama, terutama di level pemda (sharing anggaran).

5. Gubernur dan bupati sebagai leading sector diharapkan mampu menggerakkan SDM miliknya sampai level desa untuk melakukan sosialisasi program RA di kawasan hutan, membantu dan memfasilitasi sosialisasi program strategis nasional.

6. Presiden perlu menata ulang dua perpres yang sejatinya memiliki niat baik yang sama. Penulis mengusulkan perlu dilakukan review untuk menyatukan kedua perpres tersebut, bahkan jika diperlukan diatur dalam satu peraturan, apakah inti pokoknya dimasukkan dalam RUU Pertanahan (jika RUU ini masih dibahas di DPR) kemudian dibuat aturan teknisnya, atau dua perpres (Perpres No. 88 Tahun 2017 dan Perpres No. 86 Tahun 2018) dijadikan satu.

7. Dalam jangka pendek, perlu dilakukan review atas Permenko No. 3 Tahun 2018 terkait alur pelepasan kawasan hutan untuk PPTKH, tujuannya menyederhanakan proses pelepasan kawasan hutan untuk objek TORA. Juga diharapkan me-review Permen LHK P. 42/2019 terkait alur pelepasan kawasan hutan yang cukup panjang, karena harus melewati Tim Terpadu dan pencadangan. Basis Peta Indikatif dapat dimanfaatkan sebagai ukuran untuk rekomendasi pelepasan kawasan hutan untuk Objek TORA.

8. Pelu juga melakukan review dengan tujuan merevisi Permen LHK P.42/2019 terkait pelepasan kawasan hutan untuk TORA yang alurnya cukup panjang, karena harus melewati Tim Terpadu (Timdu) dan pencadangan.

9. KLHK, Kementerian ATR/BPN, gubernur/bupati, dan pengusaha HGU harus duduk bersama menyelesaikan objek-objek kawasan hutan 20\% yang sudah dilepaskan, agar bisa dipastikan lahannya untuk masyarakat yang berhak.

\section{Daftar Pustaka}

Adamopolous, T., \& Restuccia, D. (2020). "Land reform and productivity: a quantitative analysis with micro data." American Economic Journal: Macroeconomics, 12 (3):1-39.. DOI: 10.1257/mac.20150222

Akinola, A.O. (2018). Land reform in South Africa: an appraisal, Africa Review, 10 (1), 1-16, DOI: 10.1080/09744053.2017.1399560 
Borras JR, S.M., \& Franco, J.C. (2010). Contemporary discourses and contestations around pro-poor land policies and land governance. Journal of Agrarian Change, 10(1). https://doi.org/10.1111/j.14710366.2009.00243.X

Dempo, A.A.P., Salim, M.N., Farid, A.H. (2021). Evaluasi pelaksanaan redistribusi tanah eks kawasan hutan di Kabupaten Musi Rawas", Jurnal Tunas Agraria, 4 (1), DOI: https://doi.org/10.31292/jta. v4i1.131, https://jurnaltunasagraria.stpn.ac.id/JTA/article/view/131

Dhiaulhaq, A. \& McCarthy, J.F. (2020). Indigenous rights and agrarian justice framings in forest land conflicts in Indonesia, The Asia Pacific Journal of Anthropology, 21 (1), 34-54, DOI: https://doi.org /10.1080/14442213.2019.1670243

Ekawati, F.N.F., Salim, M.N., Utami, W. (2019). Pemetaan partisipatif guna pengusulan tanah obyek reforma agraria (TORA) dalam kawasan hutan di Kabupaten Ogan Komering Hulu, Jurnal Tunas Agraria 2 (3), 24-48. DOI: https://doi.org/10.31292/jta.v2i3.37, http://jurnaltunasagraria.stpn. ac.id/JTA/article/view/37

Fraser, A. (2008). Geography and land reform, Geographical Review, 98 (3), 309-321, DOI: 10.1111/j.19310846.2008.tboo303.x

Gilbert, D.E., \& Afrizal. (2019). The land exclusion dilemma and Sumatra's agrarian reactionaries, The Journal of Peasant Studies, 46 (4), 681-701, DOI: 10.1080/03066150.2017.140499o

Jakaza, E. (2019). Land reform costly": zimbabwe land reform negation discourse in the print media, Language Matters, 50 (1), 102-114, DOI: 10.1080/10228195.2018.1524922

KLHK. (2018a). Evolusi kawasan hutan, tora dan perhutanan sosial", paparan Menteri Lingkungan Hidup dan Kehutanan pada diskusi media FMB9 (Forum Merdeka Barat 9), Jakarta, 3 April.

KLHK. (2018b). Surat Menteri Lingkungan Hidup dan Kehutanan, No. S.384/MenLHK/Setjen/ Pla.2/11/2018 tentang Laporan Progress Reforma Agraria dan Sertifikasi Tanah dari Alokasi Kehutanan.

Kurniawati, F., Kistiyah, S., Luthfi, A.N. (2019). Faktor-faktor yang memengaruhi keberhasilan pelaksanaan redistribusi tanah bekas kawasan hutan, Jurnal Tunas Agraria, 2 (3), DOI: https:// doi.org/10.31292/jta.v2i3.47; http://jurnaltunasagraria.stpn.ac.id/JTA/article/view/47

Lanzona, Jr., L.A. (2019). Agrarian reform and democracy: lessons from the Philippine Experience", Millennial Asia, 10 (3), 272-298. DOI: 10.1177/0976399619879866.

Li, T.M. (2021). Commons, co-ops, and corporations: assembling Indonesia's twenty-first century land reform, The Journal of Peasant Studies, DOI: 10.1080/03066150.2021.1890718

Lucas, A., \& Warren, C. (2007). The state, the people, and their mediators: the struggle over agrarian law reform in post-new Order Indonesia. Indonesia, No. 76 (Oct., 2003), pp. 87-126. http://cip. cornell.edu/DPubS? service=Repository\&version=1.o\&verb=Disseminate\&view=body\&content type=pdf_1\&handle=seap.indo/1106934993\#

Luthfi, A.N. (2018). Reforma kelembagaan dalam kebijakan reforma agraria era Joko Widodo-Jusuf Kalla', Bhumi, Jurnal Agraria dan Pertanahan, 4 (2), 140-163. DOI: https://doi.org/10.31292/jb.v4i2.276

Platteau, J.P. (1996). The evolutionary theory of land rights as applied to Sub-Saharan Africa: A critical assessment. Development and Change. 27(1), 29-86. Doi:10.1111/j.1467-7660.1996.tboo578.x

Rachman, N.F. (2017). Land Reform dan gerakan agraria Indonesia, Insist Press, Yogyakarta.

Ramutsindela, M., \& Hartnack, A. (2019). Centring ordinary people:grounded approachestoland reform in Southern Africa, Anthropology Southern Africa, 42 (3), 195-201, DOI:10.1080/23323256.2019.1679028

Salim, M.N. (2017). Mereka yang dikalahkan: perampasan tanah dan resistensi masyarakat Pulau Padang, STPN Press, Yogyakarta.

Salim, M.N., Pinuji, S. Utami, W. (2018). Reforma agraria di kawasan hutan Sungaitohor, Riau:pengelolaan Perhutanan Sosial di wilayah perbatasan', BHUMI: Jurnal Agraria dan Pertanahan 4 (2), 164-189. DOI: https://doi.org/10.31292/jb.v4i2.277. http://jurnalbhumi.stpn.ac.id/JB/article/view/277 
Salim, M.N., \& Utami, W. (2019). Reforma agraria, menyelesaikan mandat konstitusi, STPN Press, Yogyakarta.

Salim, M.N., Utami, W., dan Wulan, D.R. (2019). Penyelesaian penguasaan tanah dalam kawasan hutan melalui skema reforma agraria, dalam Luthfi, A.N. \& Utami, W. Himpunan policy brief: Permasalahan dan Kebijakan Agraria, Pertanahan, dan Tata Ruang di Indonesia, Yogyakarta, STPN Press.

Salim, M.N., Wulan, D.R.,Pinuji, S., (2021). Reconciling community land and state forest claims in Indonesia: A case study of the Land Tenure Settlement Reconciliation Program in South Sumatra, Forest and Society, 5 (1), https://doi.org/10.24259/fs.v5i1.10552

Sirait, M.T. (2017). Inklusi, eksklusi dan perubahan agraria: redistribusi tanah kawasan hutan di Indonesia, Yogyakarta: STPN Press.

Siscawati, M., Banjade M.R., Liswanti, N., Herawati, T., Mwangi, E., Wulandari, C., Tjoa, M., and Silaya, T. (2017), Overview of forest tenure reforms in Indonesia, Working paper 223, Center for International Forestry Research (CIFOR). Bogor, Indonesia. DOI: https://doi.org/10.17528/cifor/oo6402

Steinebach, S. (2017). Farmers and pawns: The role of migrants in agrarian conflicts and rural resistance in Sumatra, Indonesia, The Asia Pacific Journal of Anthropology, 18 (3), 228-245, DOI: http:// dx.doi.org/10.1080/14442213.2017.1304443

Tenrisau, A. (2021). Laporan Dirjen Penataan Agraria Kementerian Agraria dan Tata Ruang/Badan Pertanahan Nasional, "Reforma agraria untuk keadilan dan kesejahteraan rakyat", Disampaikan dalam Rangka Rapat Kerja Teknis Reforma Agraria Tahun 2021, Jakarta, 25 Maret 2021.

Tjandra, S. (2020). Executive brief 3, pembangunan GTRA pusat \& GTRA daerah. https:// toolsfortransformation.net/indonesia/wp-content/uploads/2017/05/ExBrief_PembangunanGTRA-Pusat-dan-Daerah.pdf

Utami, W., Salim, M.N., Mujiati. (2019). Reforma agraria: tanah obyek reforma agraria (TORA) Sumatera Selatan dan dinamika pelaksanaanya, Yogyakarta: PPPM-STPN.

Webgis KLHK. http://webgis.menlhk.go.id:8o8o/kemenhut/index.php/id/peta/tora

\section{Peraturan}

Peraturan Presiden Nomor 88 Tahun 2017 tentang Penyelesaian Penguasaan Tanah Dalam Kawasan Hutan.

Peraturan Presiden Nomor 86 Tahun 2018 tentang Reforma Agraria.

Peraturan Menteri Koordinator Bidang Perekonomian Nomor 3 Tahun 2018 tentang Pedoman Pelaksanaan Tugas Tim Inventarisasi dan Verifikasi Penguasaan Tanah dalam Kawasan Hutan.

Peraturan Menteri Lingkungn Hidup dan Kehutanan Nomor 17/MENLHK/SETJEN/KUM.1/5/2018 tentang Tata Cara Pelepasan Kawasan Hutan dan Perubahan Batas Kawasan Hutan untuk Sumber Tanah Objek Reforma Agraria.

Peraturan Menteri Kehutanan Nomor. P.62/Menhut-II/2013 Tentang Perubahan Atas Peraturan Menteri Kehutanan Nomor P.44/MENHUT-II/2012 tentang Pengukuhan Kawasan Hutan.

Peraturan Menteri KLHK P. 42/2019 tentang Tata Cara Pelepasan Kawasan Hutan dan Perubahan Batas Kawasan Hutan untuk Sumber Tanah Obyek Reforma Agraria.

Keputusan menteri Lingkungan Hidup dan Kehutanan RI No. SK. 5050/MENLHK-PKTL/KUH/ PLA.2/9/2020 tentang Peta Indikatif Alokasi Kawasan Hutan untuk Penyediaan SUmber Tanah Obyek Reforma Agraria (TORA Revisi V), http://appgis.menlhk.go.id/appgis/Peta_TORA_Rev_V/ SK\%2oTORA\%2oREVISI\%2oV.pdf 